\title{
Induction of the Hahsp17.7G4 Promoter by Root-Knot Nematodes: Involvement of Heat-Shock Elements in Promoter Activity in Giant Cells
}

\author{
Carolina Escobar, ${ }^{1}$ Marta Barcala, ${ }^{1}$ Mary Portillo, ${ }^{1,2}$ Concepción Almoguera, ${ }^{3}$ Juan Jordano, ${ }^{3}$ and \\ Carmen Fenoll ${ }^{1}$ \\ ${ }^{1}$ Facultad de Ciencias del Medio Ambiente, Universidad de Castilla-La Mancha, Campus de la Real Fábrica de Armas, \\ E-45071 Toledo, Spain; ²Departamento de Biología, Universidad Autónoma de Madrid, Cantoblanco, E-28049 Madrid, \\ Spain; ${ }^{3}$ Instituto de Recursos Naturales y Agrobiología, CSIC, Avenida Reina Mercedes 10, E-41012 Sevilla, Spain
}

Submitted 13 November 2002. Accepted 20 June 2003.

Root-knot nematodes feed from specialized giant cells induced in the plants that they parasitize. We found that the promoter of the Hahsp17.7G4 gene, which encodes a small heat-shock protein involved in embryogenesis and stress responses, directed GUS expression in tobacco galls induced by the root-knot nematode Meloidogyne incognita. In roots containing a GUS reporter fusion to the Hahsp17.7G4 promoter, $10 \%$ of the galls stained for GUS expression 1 to 3 days after infection and the fraction stained increased to 60 to $80 \% 17$ to 20 days after infection. A DNA fragment from -83 to +163 , which contains heat-shock element (HSE) core sequences, is sufficient to support a promoter activity largely restricted to giant cells within the galls. Two-point mutations in HSE cores, previously reported to abolish the heat-shock response and to strongly reduce the embryogenesis response of the same promoter, did not reduce expression in giant cells. This suggests a distinct regulation of the promoter by nematodes. However, additional point mutations located at positions crucial for binding of heat-shock transcription factors (HSFs) caused a severe decrease in the nematode response. These results demonstrate that HSEs are involved in the promoter activation in giant cells and suggest that HSFs may mediate this response.

Root-knot nematodes use poorly understood mechanisms to maintain the specialized cells (giant cells) that constitute their feeding sites. The dramatic changes leading to the differentiation of a giant cell are known to involve changes in gene expression (Fenoll et al. 1997; Gheysen and Fenoll 2002). Several studies have reported differential promoter activity in nematode feeding sites (NFSs) (Barthels et al. 1997; Bertioli et al. 1999; Escobar et al. 1999; Favery et al. 1998; Gheysen and Fenoll 2002; Goddijn et al. 1993; Møller et al. 1998; Niebel et al. 1996; Opperman et al. 1994; Puzio et al. 1999; Urwin et al. 1997), but identification and analysis of minimal regulatory sequences from these nematode-activated promoters is scarce. Nematode induction of the promoters of TobRB7, AtPYK10, AtPYK20, and CaMV35S, among others, have been studied by deletion analysis (Bertioli et al. 1999; Nitz et al. 2001; Opperman

Corresponding authors: C. Escobar, Telephone: +34925268800 ext: 5434; Fax: 3492526 8840; E-mail: carolina.escobar@uclm.es; and C. Fenoll, Telephone: +34 925265715; Fax: 3492526 8840; E-mail: carmen.fenoll@uclm.es et al. 1994; Puzio et al. 1999). Furthermore, putative cis elements associated with NFS expression have been proposed based only on in vitro analysis evidence (Escobar et al. 1999, 2001). Similarly, a few genes encoding putative transcription factors have been reported as expressed in NFSs. Among them are $P Y K 20$, which codes for a protein with a glutamine-rich domain (Puzio et al. 1999); WRKY1, which belongs to a large family of genes with different roles in plant defense and development (Gheysen and Fenoll 2002); $A B I 3$, whose promoter is induced in syncytia (Gheysen and Fenoll 2002), and KNOX and PHAN, which encode transcription factors required for meristem establishment and whose transcripts accumulate in giant cells (Koltai et al. 2001). However, no functional analyses have been reported so far to demonstrate a role of such putative transcription factor genes in NFSs. Thus, a detailed analysis of regulatory sequences in nematode-inducible promoters and of their interacting transcription factors will contribute to the understanding of the regulatory signal transduction pathways involved in the dramatic changes in gene expression that occur in NFSs.

Several genes induced by nematode infection also are activated during embryogenesis, such as the embryogenesisspecific ABI3 (Gheysen and Fenoll 2002) and genes encoding LEA-like proteins (Gheysen et al. 1996; Vaghchhipawala et al. 2001; Van der Eycken et al. 1996), which also are induced during desiccation processes. One group of genes that is induced during the late desiccation stages of embryo development encodes small heat-shock proteins (sHSPs) (Almoguera et al. 1998; Coca et al. 1996; Prändl and Schöffl 1996; Wehmeyer et al. 1996). Several studies indicate the participation of heatshock factors (HSFs) as well as additional transcription factors in the regulation of sHSP expression during development and in response to environmental cues (Almoguera et al. 1998; Carranco et al. 1999; Dong and Dunstan 1996; MedinaEscobar et al. 1998; Rojas et al. 1999 Wehmeyer and Vierling 2000; Zimmerman et al. 1989). There also are reports of differential regulation of sHSPs by pathogen attack, such as during fungal haustorium formation (Tada et al. 2000), and of HSP70 during viral infections (Aranda et al. 1999). Moreover, cyst nematodes induce the accumulation of a heat-shock protein (HSP70) transcript in soybean (Vaghchhipawala et al. 2001).

In this study, we demonstrate that the promoter of Hahsp17.7G4, a gene that encodes a sunflower sHSP, is activated in giant cells formed after Meloidogyne incognita infection in transgenic tobacco plants. A translational GUS fusion carrying a promoter region of only $83 \mathrm{bp}$ contains the regu- 
latory sequences sufficient for its nematode-dependent activation. Furthermore, point mutations in heat-shock element (HSE) cores crucial for HSF binding caused a severe decrease in the nematode response. This fact suggests an involvement of HSEs and, possibly, of HSFs in promoter activation in giant cells.

\section{RESULTS}

The Hahsp17.7G4 promoter is active in giant cells.

To analyze the inducibility of the Hahsp $17.7 G 4$ promoter by root-knot nematodes, we used transgenic tobacco plants that carried a fusion of the Hahsp17.7G4 promoter (up to position $-1,132)$ linked to the reporter gene uidA (GUS) (Coca et al. 1996). Several independent transgenic lines (see Material and Methods) were infected with $M$. incognita, and GUS activity was determined at two time points after infection. Under the conditions used in the assays, roots showed no detectable GUS activity, while intense GUS staining was detected in galls (Fig. 1A). Thin sections showed a strong localized signal in the giant cells (Fig. 1B). On some occasions, a weak staining was observed in the cell layers adjacent to the giant cells (Fig. 1B). We attribute this signal to some diffusion of GUS reaction product or to some expression in the surrounding cells, because this appeared sporadically. At early infection stages (1 to 7 days post infection [dpi]), the percentage of stained galls was low $(\approx 10 \%)$. However, there was an increase during the infection period, reaching values of 60 to $80 \%$ at 13 to $20 \mathrm{dpi}$ in most of the plant lines (Fig. 2A and B).

\section{The proximal region of the Hahsp17.7G4 promoter is sufficient to confer expression in galls.}

Transgenic plants carrying $5^{\prime}$ truncations of the Hahsp17.7G4 promoter to positions -395 and -83 bp showed induction of GUS in galls very similar to that of the control $(-1,132::$ GUS) lines (Fig. 1C and E). Plants with the two deleted promoter constructs showed higher frequencies of stained galls compared with the control, both at early and later infection stages (Fig. 2B). However, statistical analysis indicates that no significant differences were observed between the control and each of the deleted transformants in pairwise comparisons by the U-Mann-Whitney test $(-1,132::$ GUS/-395::GUS, $P=$ $0.375 ;-1,132::$ GUS/-83::GUS, $P=0.306)$. Tissue localization in the tobacco lines with deleted promoters showed that the signal also was concentrated strongly in giant cells (Fig. 1D and F). Both constructs exhibited higher frequency of stained galls at later infection stages, as did the transformants with the longest promoter version (Fig. 2B). A more detailed time course of stained galls in the two deleted lines showed a clear increase in the frequency of blue galls along the infection period, starting at values of $\approx 10 \%$ at 1 to $3 \mathrm{dpi}$, and reaching a value close to $80 \%$ at the latest infection stages (17 to $20 \mathrm{dpi}$ ) tested (Fig. 2A). These results indicate that a region of $83 \mathrm{bp}$ in the Hahsp17.7G4 promoter is sufficient to maintain the induction pattern observed in galls with the longest $(-1,132 \mathrm{bp})$ promoter version tested, both temporally and spatially (Figs. 1 and 2).

\section{Four point mutations in the HSEs of the Hahsp17.7G4 promoter abolish its nematode inducibility.}

The minimal promoter region sufficient for nematode-inducibility contains several HSE core sequences (Almoguera et al., 1998; Coca et al. 1996) (Fig. 3). To determine the involvement of these HSE cores in nematode inducibility, plants containing a mutated version of the $-1,132:$ GUS gene (mutant A) (Almoguera et al. 1998) (Fig. 3) that affected two different HSE core sequences (Fig. 3, first and third HSE cores of box I) were infected with $M$. incognita and stained for detection of GUS activity at different time points after infection. GUS staining was localized in the center of the gall, with a strong signal in giant cells (Fig. 4A and B). The two nucleotide substitutions in box I of mutant A (Fig. 3) had no obvious qualitative effect on GUS expression, because the staining pattern was comparable to that of the $-1,132$-bp control line (compare Figs. 1 and 4, panels A and B). Moreover, there were no significant differences in the percentage of blue galls in pairwise comparisons by the U-Mann-Whitney analysis between mutant $A$ and the rest of the transformants $(-1,132::$ GUS/mutant A::GUS, $P=0.074$; $-395:: G U S / m u t a n t$ A::GUS, $P=0.157$; and $-83:: G U S / m u t a n t$ A::GUS, $P=0.157$. Therefore, the mutant A promoter behaved similarly to the wild-type promoter $(-1,132::$ GUS $)$ and to the two deletion versions tested (-395::GUS and $-83::$ GUS).

Plants containing additional mutations in box I and box II also were tested. We used mutant E (Fig. 3) because it carries two mutations in box I which are essential for HSF binding and which render the promoter nonresponsive to embryogenesis and heat shock (Almoguera et al. 1998). Thus, we could establish similarities or differences in the promoter regulation between these processes and the nematode response. Compared with mutant $\mathrm{A}$, mutant $\mathrm{E}$ carries two extra point mutations in box II (second and fourth HSE cores) and two extra point mutations in box I (third and sixth HSE cores). In mutant E plants, nematode inducibility was almost completely abolished at all infection times tested (Figs. 4C and D, and 2B). Differences between mutant $\mathrm{E}$ and each of the constructs (control, deletions, and mutant A) were significant (mutant E::GUS/ -1,132:: GUS, /-395::GUS, /-83::GUS, and /mutant A::GUS; $P=0.04,0.027,0.014$, and 0.025 , respectively). Thus, the four extra point mutations present in mutant $\mathrm{E}$ compared with mutant A impaired nematode-mediated promoter activation.

\section{DISCUSSION}

\section{A short fragment of the Hahsp17.7G4 gene drives} giant cell expression in transgenic tobacco plants.

Our results demonstrate that the Hahsp17.7G4 promoter is active in tobacco galls induced by $M$. incognita. The promoter is activated from early stages of infection ( 1 to 5 days), similarly to other nematode-inducible promoters related to embryogenesis or cell water deficit, such as LEMMI9 or LEA14A (Escobar et al. 1999; Gheysen et al. 1996). However, Hahsp 17.7G4 promoter activity appears to be restricted to giant cells and, to a lesser extent, some immediately adjacent cells, whereas LEMMI9 also is expressed in vascular tissues surrounding the gall and $L E A 14 A$ is not expressed in giant cells, but in the rest of the gall. Maximum Hahsp17.7::GUS activity was detected 13 to $20 \mathrm{dpi}$ (Fig. 2), indicating that the promoter is active throughout early to middle infection stages. This suggests that the promoter activity may be more related to tissue (giant cells) differentiation than to an immediate response to infection.

The deletion analysis showed that the tobacco lines carrying the construct that included only 83 bp upstream from the transcription start point was as active in galls as the longest promoter version tested (Figs. 1 and 2). This indicates that the region from $-1,132$ to $-83 \mathrm{bp}$ is dispensable for the activation of Hahsp17.7G4 promoter in tobacco giant cells induced by $M$. incognita. Therefore, a minimal nematode-inducible promoter region that comprises the $83 \mathrm{bp}$ upstream from the transcription start point has been identified (Fig. 3).

\section{Involvement of HSEs in giant cell expression.}

The effect of specific mutations in the HSE regions of Hahsp17.7G4 on its nematode inducibility suggests that a minimal HSE, including five HSE cores, is crucial for the 
A

B
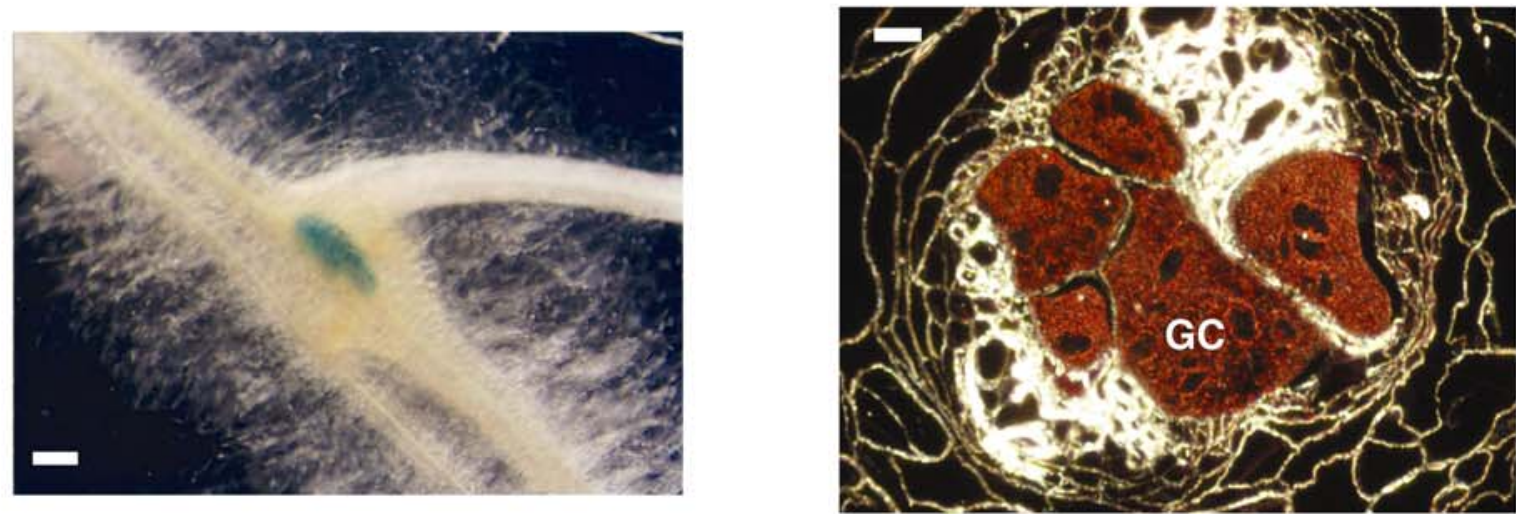

\section{-1132 bp}

C

D
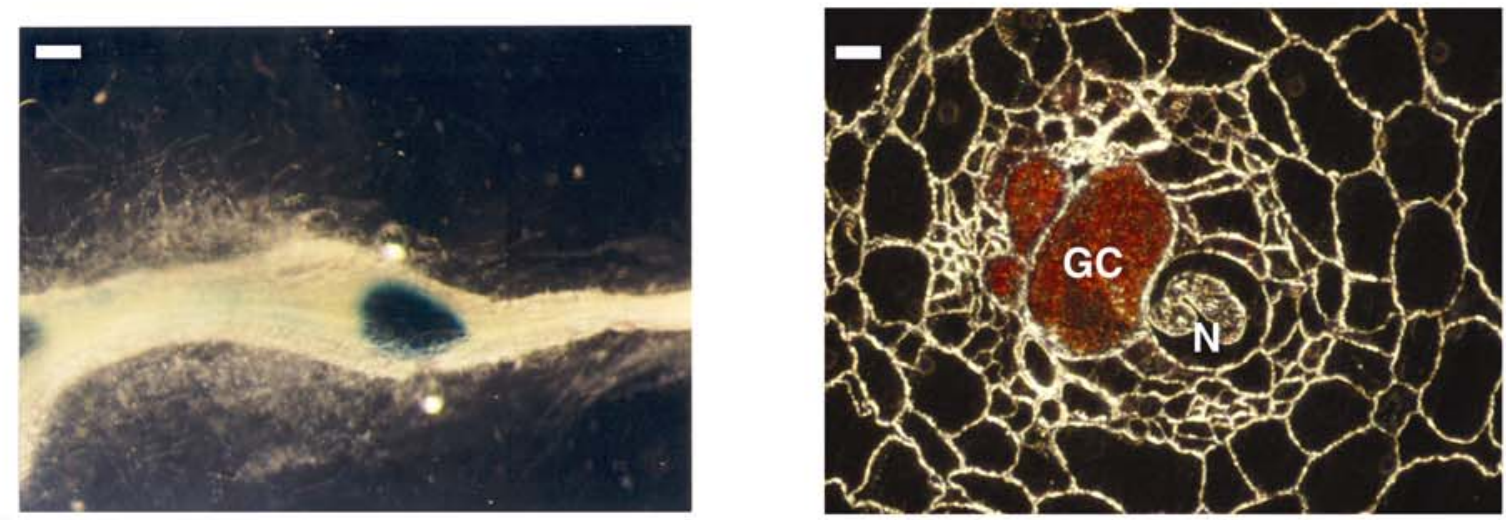

\section{-395 bp}

E
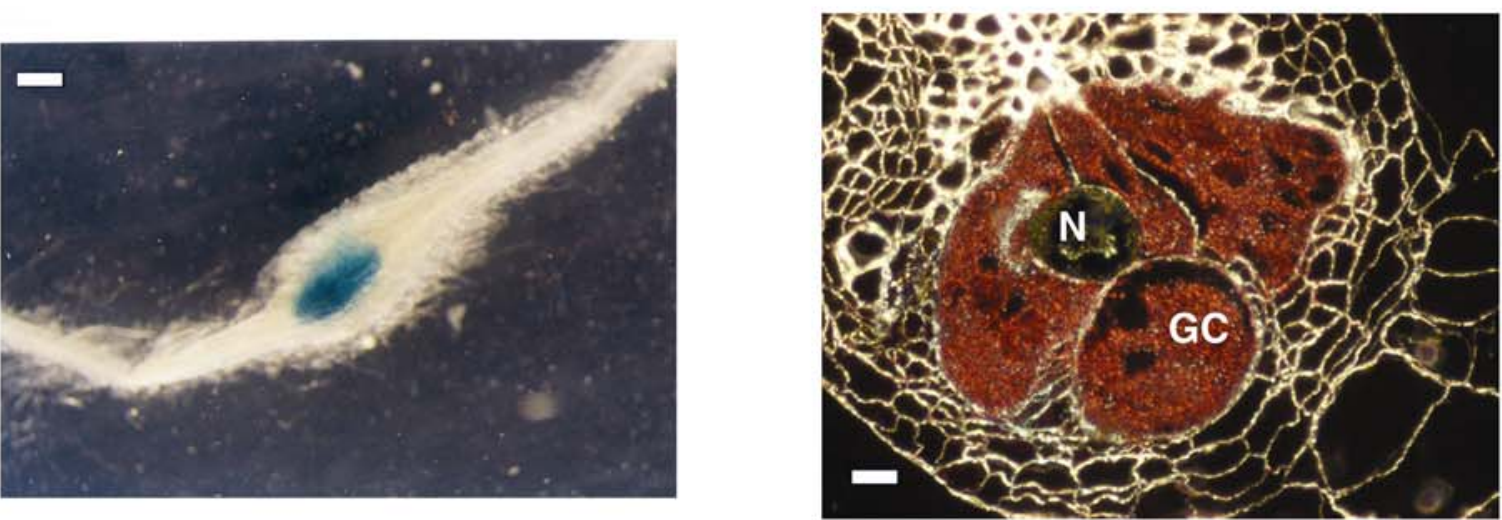

\section{$-83 b p$}

Fig. 1. Activity of various Hahsp17.7G4 promoter versions analyzed by GUS staining in tobacco plants infected with Meloidogyne incognita. Whole mounts (left panels) show GUS activity in galls of representative transformant lines containing wild type and deleted promoter versions (A, $-1,132::$ GUS; C, $-395::$ GUS; E, $-83:$ GUS). Thin sections $(10 \mu \mathrm{M})$ of galls 10 to 15 days after $M$. incognita infection (right panels) localize GUS activity mainly in giant cells (B, $-1,132::$ GUS, D, $-395::$ GUS; F, $-83::$ GUS). GC, giant cells and N, nematode. Scale bars: $\mathbf{A}$ and $\mathbf{C}, 420 \mu \mathrm{m} ; \mathbf{E}, 525 \mu \mathrm{m}$; and $\mathbf{B}, \mathbf{D}$, and F, 25 $\mu \mathrm{m}$. GUS staining is observed as blue color in whole mounts and as a red precipitate in the dark field micrographs of the sections. 
nematode inducibility (Fig. 3). Mutant A plants and plants with the wild-type version of the promoter were similarly induced in giant cells, both in terms of cell specificity and temporal regulation. In contrast, the two HSE point mutations in mutant A caused a severe depletion of heat shock and late embryogenesis responses (Almoguera et al. 1998). Mutant E, which has four extra point mutations at positions crucial for HSF binding (Almoguera et al. 1998) (Fig. 3), showed no detectable induction in galls (Figs. 2 and 4). Both box II and the first HSE core from box I (Fig. 3) seem not to be crucial for giant cell activa-

\section{A}

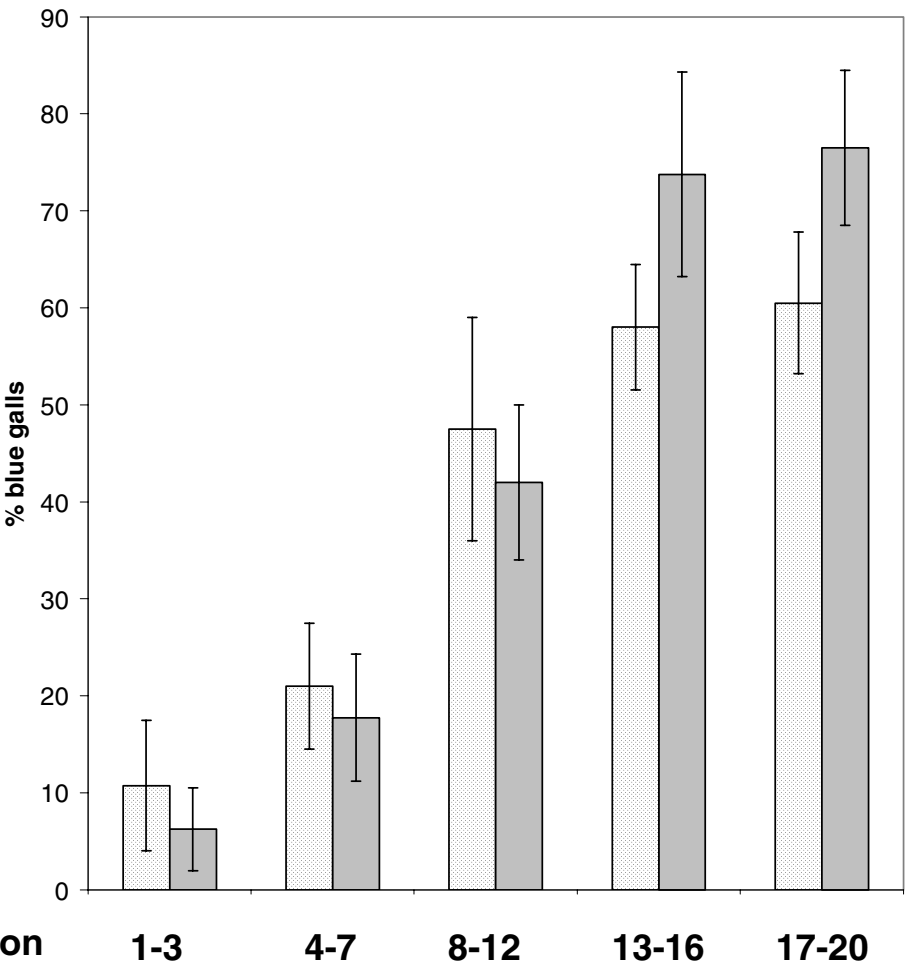

B

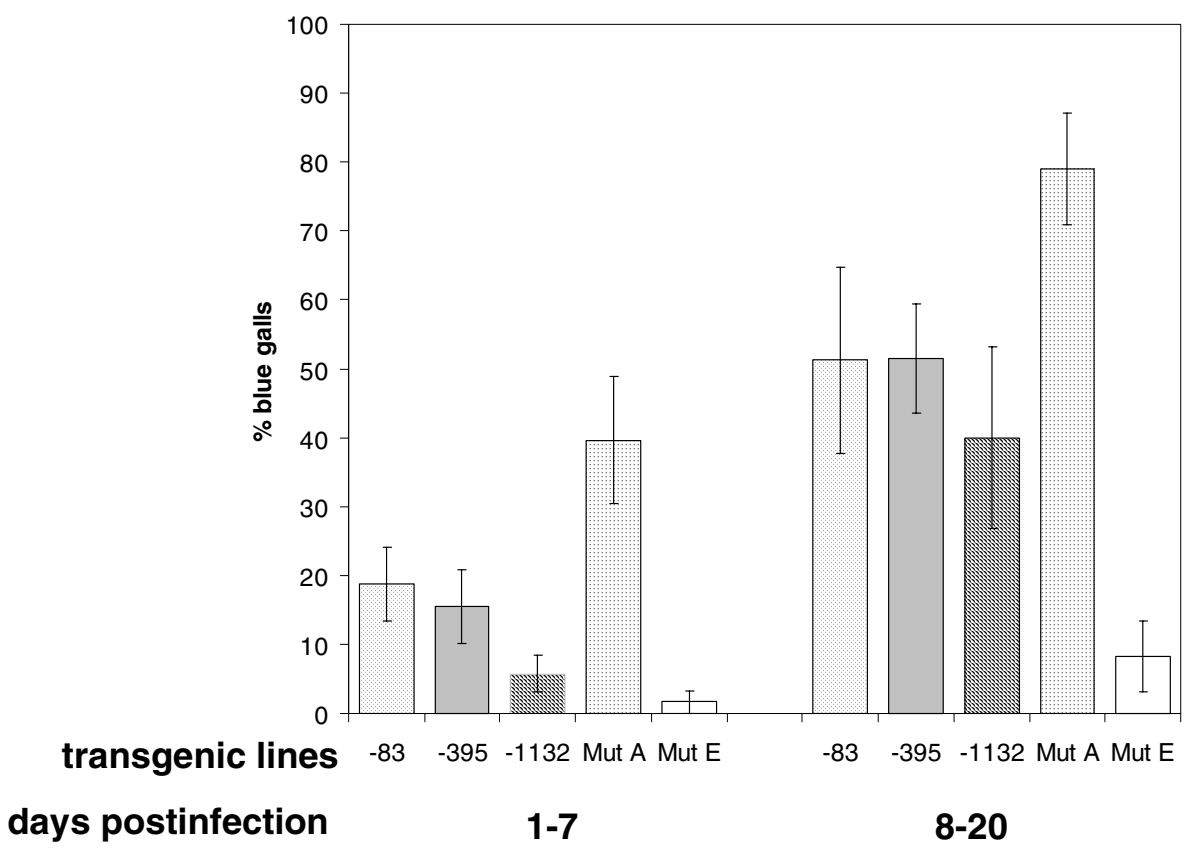

Fig. 2. Frequency of GUS activity in galls of tobacco plants transformed with different Hahsp17.7G4 promoter versions. A, Time course of the deleted promoter lines $-83::$ GUS (light gray) and -395::GUS (dark gray). B, Wild-type, deleted, and mutated promoter lines: $-1,132::$ GUS, $-83::$ GUS, $-395::$ GUS, mutant A::GUS, and mutant E::GUS. The different time intervals analyzed are indicated. Data are means of four independent plant lines for the deletions and the wild-type promoter versions, three lines for mutant A, and six lines for mutant E. Data from four independent experiments for each line were pooled. Bars represent the standard errors as deviations of the values of the different transgenic lines from the mean for each construct and time point. 
tion, because the -83 -bp deletion does not contain these sequences, but it is fully active in galls. However, we cannot exclude a contribution of these sequences, in the context of the longest promoter version, to the regulation of the Hahsp17.7 $G 4$ in galls. In contrast, the two extra mutations in the third and sixth HSE cores of box I in mutant E (Fig. 3) show a severe reduction in promoter activation in giant cells. Therefore, these core nucleotides in box I (Fig. 3) could be considered crucial for the nematode inducibility of Hahsp17.7 G4, and mutant E behavior in this response should reflect mostly the effect of the mutations in the third and sixth cores of box I.

HSEs mediate transcription of heat-shock-responsive promoters through their interaction with HSFs (Schöffl et al. 1998). Thus, it is probable that giant cell activity of the

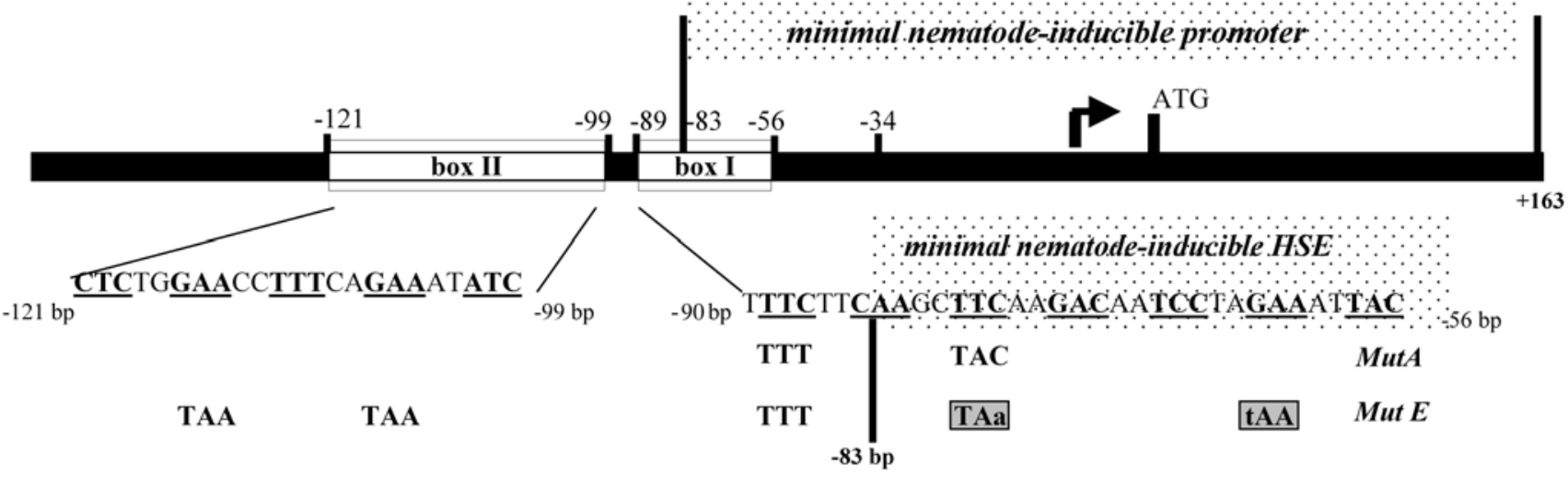

Fig. 3. Proximal Hahsp17.7G4 gene promoter region. The transcription start point (arrow) and the ATG for translation initiation are indicated. The sequences from position -83 bp up to position +163 are included in all the constructs used in this work. The positions of the two boxes containing heatshock element (HSE) cores are shown (box I and box II) and their sequences are displayed. The core repeats crucial for heat-shock transcription factor binding in each box are indicated in bold and underlined. The core sequences changed in mutant A and mutant $\mathrm{E}$ are shown below the wild-type sequence. Nucleotide substitutions in the HSE cores potentially crucial for nematode inducibility are indicated in lower case and the cores identified by gray boxes. The dotted bar at the top represents the minimal region of the gene required for giant cell expression as delimited in this work, and the dotted bar at the bottom represents the minimal nematode inducible HSE identified in the -83::GUS construct.

A

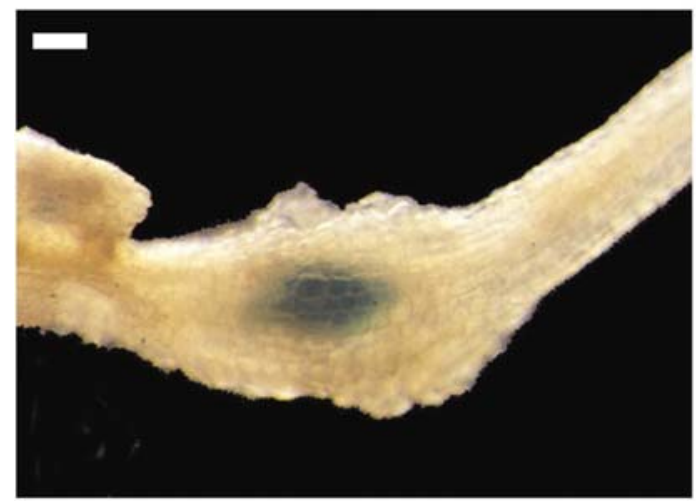

C

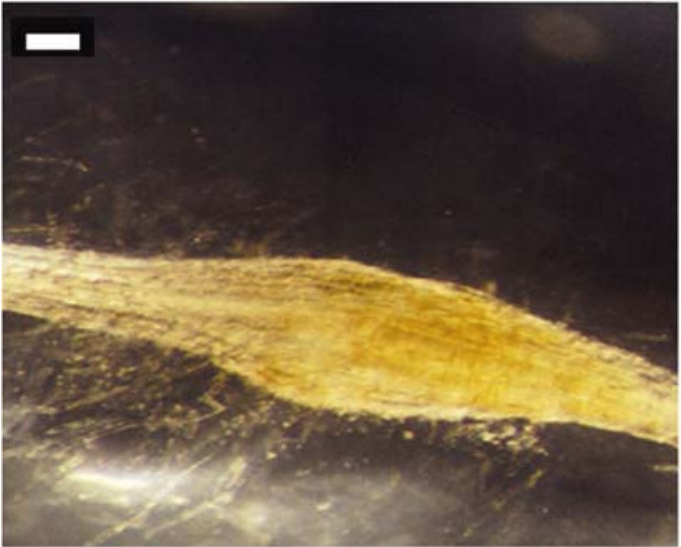

B

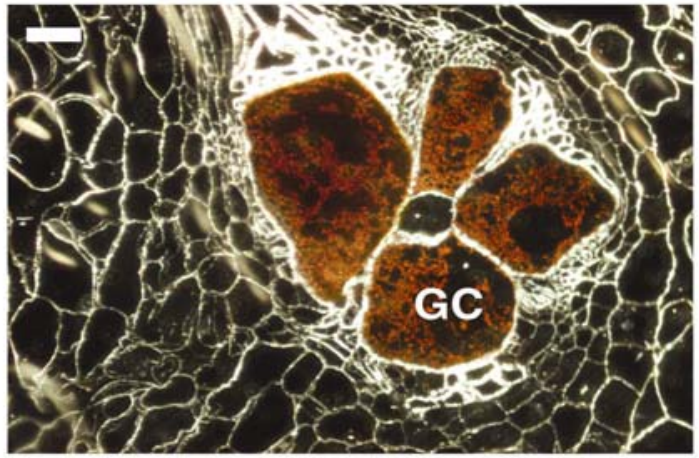

D

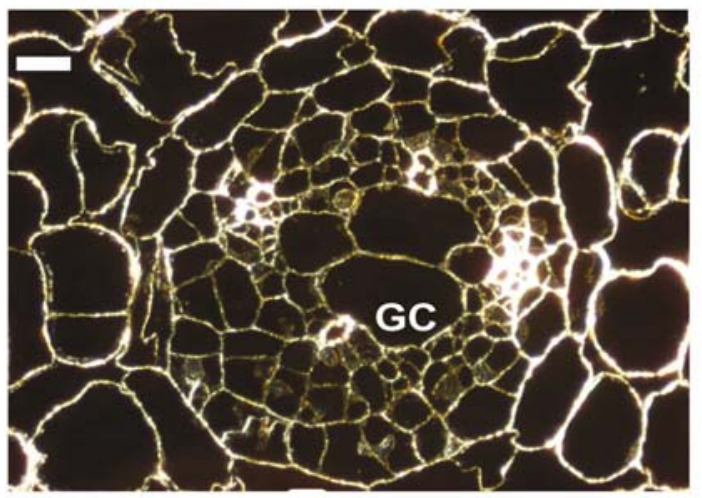

Fig. 4. Activity of mutated versions of the Hahsp17.7G4 promoter analyzed by GUS staining in representative transformed tobacco lines infected with Meloidogyne incognita. Left panels show whole mounts of infected roots (A, mutant A::GUS; C, mutant E::GUS). Right panels show thin sections (10 $\mu \mathrm{M}$ ) of galls 10 to 15 days after infection (B, mutant A::GUS; D, mutant E::GUS). GC, giant cells. Scale bars: A and $\mathbf{C}, 328 \mu \mathrm{m} ; \mathbf{D}, 25 \mu \mathrm{m} ;$ and $\mathbf{B}, 50 \mu \mathrm{m}$. GUS staining is observed as blue color in whole mounts, and as a red precipitate in the dark field micrographs of the sections. 
Hahsp17.7 promoter involves HSFs, because mutations described to impair HSF binding (Almoguera et al. 1998), such as those present in mutant $\mathrm{E}$, abolish nematode induction.

How is giant cell activation of the Hahsp17.7 promoter related to its activation during heat shock and embryogenesis? The -83-bp promoter version essentially retained the regulation in the three processes, indicating that sufficient elements required for all of them are present in this sequence. The HSE positions mutated in mutant $\mathrm{A}$ are dispensable only for nematode induction. Therefore, at least part of the HSE (and hence HSF)-mediated responses during heat shock and embryogenesis do not seem to be crucial for giant cell expression. However, the additional mutations in mutant $\mathrm{E}$ abolished nematode inducibility as well as the late-embryogenesis and heat-shock responses (Almoguera et al. 1998). This suggests that common HSE cores in box I are essential for the three responses. As with Hahsp17.7, HSP70 expression during viral infection seems to be regulated through pathways different from those operating in the heat-shock response, because the HSF needed for HSP70 transcription in the heat-shock response is not present during viral infection (Aranda et al. 1999).

Sequence elements other than HSE present in the -83 -bp promoter version also may contribute to the nematode inducibility of the Hahsp17.7G4 promoter. All promoter constructs analyzed were translational fusions and included, besides the promoter region, an additional $163 \mathrm{bp}$ downstream from the transcription initiation site. A search for putative cis elements in the $246 \mathrm{bp}$ that constitute the minimal nematode-inducible sequence using three different data bases, TRANSFAC (Wingender et al. 2000), PLACE (Higo et al. 1999), and PLANTCARE (Rombauts et al. 1999), identified a number of homologies to known regulatory sequences from other plant genes (data not shown). The most remarkable putative cis elements overlapping HSEs are the CCAAT boxes, which are known to interact with HSEs enhancing the expression of chimaeric heat-shock genes in transgenic tobacco (Rieping and Schöffl 1992) and which might play a quantitative role on Hahsp17.7G4 expression in galls. However, the participation of any of these cis elements on nematode inducibility of this promoter remains purely speculative until functional analyses are performed.

The present study is based on the analysis of the plant response to nematodes in a heterologous system. Preliminary results from our laboratory indicate that the longest promoter construct, $-1,132 \mathrm{bp}$, also is active in galls formed in Arabidopsis spp. (C. Escobar, M. Portillo, M. Barcala, and C. Fenoll, unpublished data). This suggests that common regulatory components in both heterologous plant systems (tobacco and Arabidopsis spp.) can mediate the induction of the sunflower Hahsp17.7G4, and reinforces the idea of a general mechanism involved in regulation of expression of this specific gene in root-knot nematode giant cells.

Our data pose the question of why HSP genes are activated in giant cells. The fact that the Hahsp17.7 promoter is induced in giant cells does not necessarily imply that the gene product accumulates in such cells or that, if it does, it plays a role in giant cell ontogeny or function. However, HSP70 transcripts also have been shown to accumulate in roots infected by cyst nematodes (Vaghchhipawala et al. 2001), and viral infection also triggers HSP70 transcript accumulation (Aranda et al. 1999). Work is in progress to determine whether the Hahsp17.7G4 transcript and protein are present in giant cells as a first step to assess the involvement of sHSPs in giant cell functioning.

The specific differences between promoter regulation during embryogenesis, in response to heat stress, and in giant cells that we have identified could be exploited to engineer giant cell-specific chimeric promoters that will knock out the heat shock and late embryogenesis responses, while allowing giant cell expression.

\section{MATERIALS AND METHODS}

\section{Nematode populations and infections.}

An $M$. incognita MIK population (obtained from F. Grundler, Vienna) was maintained in vitro on cucumber roots. Egg masses were collected at maturity and used to inoculate transgenic tobacco plants grown in Gamborg medium (Gamborg et al. 1968) supplemented with sucrose at $15 \mathrm{~g} / \mathrm{liter}$, at 27 to $28^{\circ} \mathrm{C}$, a $16-\mathrm{h}$ photoperiod, and $70 \%$ humidity. Galls were monitored visually every $24 \mathrm{~h}$ after inoculation for at least 7 days, and newly formed galls were individually labeled. Therefore, gall age could be determined with an error of \pm 1 day after infection. A minimum of 30 galls was scored in each independent experiment.

\section{Plant material.}

Transgenic tobacco plants containing different versions of the Hahsp17.7G4 promoter were described by Coca and associates (1996). We used four independent transgenic lines for the nematode infection experiments for both the full-length $(-1,132:: G U S)$ and each of the two Hahsp17.7G4 shorter promoter versions (-395::GUS and -83::GUS) (Coca et al. 1996), and three and six lines, respectively, for the mutated promoter constructs (mutant A and mutant E) (Almoguera et al. 1998). Seed from $\mathrm{T}_{0}$ plants were selected in MS medium (Murashige and Skoog 1962) supplemented with kanamycin at $50 \mu \mathrm{g} / \mu \mathrm{l}$. Resistant plants were transferred to soil and grown at 20 to $25^{\circ} \mathrm{C}$ and a 16-h photoperiod, and $\mathrm{T}_{1}$ seed were collected for the experiments. Transformant lines were selected among 10 to 12 lines whose responses to heat shock or during embryogenesis, adjusted to the average data, measured as GUS activity in previous works (Almoguera et al. 1998; Coca et al. 1996).

\section{Histochemical detection of GUS activity.}

Plants were stained for GUS activity in sterile conditions and at $28^{\circ} \mathrm{C}$ to avoid heat shock, as described by Almoguera and associates (1998). Whole-mount specimens were observed and photographed under a Leica binocular microscope MZ6. For tissue localization of GUS expression, root samples were washed in $10 \mathrm{mM}$ phosphate buffer, $\mathrm{pH} 7$, immediately after collection. Material was fixed in $2.5 \%$ glutaraldehide in 25 $\mathrm{mM}$ sodium phosphate buffer, $\mathrm{pH} 7$, by vacuum infiltration for $10 \mathrm{~min}$ and incubated at $4^{\circ} \mathrm{C}$ for $150 \mathrm{~min}$. After a wash in 10 $\mathrm{mM}$ phosphate buffer, $\mathrm{pH} \mathrm{7,} \mathrm{for} 10 \mathrm{~min}$, samples were dehydrated in an ethanol series, treated with $100 \%$ acetone, and subsequently embedded in 1/1 acetone/Araldyte (CY212, Taab) (vol/vol). Finally, tissue was embedded in $100 \%$ Araldyte and semithin sections $(10 \mu \mathrm{m})$ were obtained with an ultramicrotome (Reichert's ultracut S). Micrographs were taken with a stereoscopic microscope (OLYMPUS BX61).

\section{Statistical analysis of data.}

The value distributions for the percentages of GUS-stained galls were compared between plants carrying different Hahsp 17.7G4::GUS fusions by the nonparametric test of Mann-Whitney, and using the program Statistical Package for the Social Sciences (SPSS, Inc., Chicago). Pairwise comparisons between all possible groups were performed to analyze the differences of the effect of each chimeric gene in GUS expression. The level of significance was set to $P \leq 0.05$.

\section{ACKNOWLEDGMENTS}

This work was supported by grants from the European Commission (EU QLK5-1999-01501) and the Consejería de Ciencia y Tecnología de 
Castilla-La Mancha (AGRO-20092) to C. Fenoll. C. Almoguera and J. Jordano were supported by the Spanish "Comisión Interministerial de Ciencia y Tecnología" (grant BIO99-794). M. Barcala was a recipient of a graduate FPU fellowship from the Spanish Ministerio de Educación. We thank A. Aubareda for her technical contribution in setting up some of the experiments, P. Prieto for her kind help with the selection and maintenance of the biological material, D. Mejías for advice with the semithin tissue sections, A. Rapp for her help in the nematode-populations maintenance, and F. Fernández Del Campo and E. Vierling for the critical reading of the manuscript.

\section{LITERATURE CITED}

Almoguera, C., Prieto-Dapena, P., and Jordano, J. 1998. Dual regulation of a heat-shock promoter during embryogenesis: stage-dependent role of heat shock elements. Plant J. 13:437-446.

Aranda, M. A., Escaler, M., Carole, L. T., and Maule, A. 1999. A heat shock transcription factor in pea is differentially controlled by heat and virus replication. Plant J. 20:153-161.

Barthels, N., van der Lee, F. M., Klap, J., Goddijn, O. J. M., Karimi, M., Puzio, P., Grundler, F. M. W., Ohl, S. A., Lindsey, K., Robertson, L., Robertson, W. M., Van Montagu, M., Gheysen, G., and Sijmons, P. C. 1997. Regulatory sequences of Arabidopsis drive reporter gene expression in nematode feeding structures. Plant Cell 9:2119-2134

Bertioli, D. J., Smoker, M., and Burrows, P. R. 1999. Nematode-responsive activity of the cauliflower mosaic virus $35 \mathrm{~S}$ promoter and its subdomains. Mol. Plant-Microbe Interact. 12:189-196.

Carranco, R., Almoguera, C., and Jordano, J. 1999. An Imperfect heat shock element and different upstream sequences are required for the seed-specific expression of a small heat-shock protein gene. Plant Physiol. 121:723-730.

Coca, M. A., Almoguera, C., Thomas, T. L., and Jordano, J. 1996. Differential regulation of small heat-shock genes in plants: analysis of a water stress-inducible and developmentally activated sunflower promoter Plant Mol. Biol. 31:863-876.

Dong, J. Z., and Dunstan, D. I. 1996. Characterization of three heat-shock protein genes and the developmental regulation during somatic embryogenesis in white spruce (Picea glauca (Moench) Voss). Planta 200:85-91.

Escobar, C., Aristizabal, F., Navas, A., Del Campo, F. F., and Fenoll, C. 2001. Isolation of active DNA-binding nuclear proteins from tomato galls induced by root-knot nematodes. Plant. Mol. Biol. Rep. 19:375a$375 \mathrm{~h}$.

Escobar, C., De Meutter, J., Aristizábal, F., Sanz-Alférez, S., F. del Campo, F., Barthels, N., Van Der Eycken, W., Seurink, J., van Montagu, M., Gheysen, G., and Fenoll, C. 1999. Isolation of the LEMMI9 gene and promoter analysis during a compatible plant-nematode interaction. Mol. Plant-Microbe Interact. 12:440-449.

Favery, B., Lecomte, P., Gil, N., Bechtold, N., Bouchez, D., Dalmasso, A., and Abad, P. 1998. RPE, a plant gene involved in early developmental steps of nematode feedings cells. EMBO J. 17:6799-6811.

Fenoll, C., Grundler, F. M. W., and Ohl, S. A., eds. 1997. Cellular and Molecular Aspects of Plant-Nematode Interactions. Kluwer, Dordrecht, The Netherlands.

Gamborg, O. L., Miller, R. A., and Ojima, K. 1968. Nutrient requirement of suspensions cultures of soybean root cells. Exp. Cell Res. 50:151-158.

Gheysen, G., and Fenoll, C. 2002. Gene expression in nematode feeding sites. Annu. Rev. Phytopathol. 40:191-219.

Gheysen, G., Van der Eycken, W., Barthels, N., Karimi, M., and Van Montagu, M. 1996. The exploitation of nematode-responsive plant genes in novel nematode control methods. Pestic. Sci. 47:95-101.

Goddijn, O. J., Lindsey, K., van der Lee, F. M., Klap, J. C., and Sijmons, P. C. 1993. Differential gene expression in nematode-induced feeding structures of transgenic plants harboring promoter-gus A fusion constructs. Plant J. 4:863-873.

Higo, K., Ugawa, Y., Iwamoto, M., and Korenaga, T. 1999. Plant cis-acting regulatory DNA elements (PLACE) database. Nucleic Acids Res. 27:297-300.

Koltai, H., Dhandaydham, M., Opperman, C., Thomas, J., and Bird, D. 2001. Overlapping plant signal transduction pathways induced by a parasitic nematode and a rhizobial endosymbiont. Mol. Plant-Microbe Interact. 14:1168-1177.

Medina-Escobar, N., Cardenas, J., Muñoz-Blanco, J., and Caballero, J. L. 1998. Cloning and molecular characterization of a strawberry fruit ripening-related cDNA corresponding a mRNA for a low-molecularweight heat-shock protein. Plant Mol Biol. 364:33-42.

Møller, S. G., Urwin, P. E., Atkinson, H. J., and Mc-Pherson, M. J. 1998. Nematode-induced expression of ataol, a gene encoding an extracellular diamine oxidase associated with developing vascular tissue. Physiol. Mol. Plant Pathol. 53:73-79.

Murashige, T., and Skoog, F. 1962. A revised medium for rapid growth and bioassay with tobacco tissue cultures. Physiol. Plant Pathol. 15:473-497.

Niebel, A., de Almeida Engler, J., Hemerly, A., Ferreira, P., Inze, D., Van Montagu, M., and Gheysen, G. 1996. Induction of cdc2a and cyc1At expression in Arabidopsis thaliana during early phases of nematodeinduced feeding cell formation. Plant J. 10:1037-1043.

Nitz, I., Berkefeld, H., Puzio, P. S., and Grundler, F. M. W. 2001. Pyk10: a seedling and root specific gene and promoter from Arabidopsis thaliana. Plant Sci. 161:337-346

Opperman, C. H., Taylor, C. G., and Conkling, M. A. 1994. Root-knot nematode-directed expression of a plant root-specific gene. Science 263:221-223

Prändl, R., and Schöffl, T. 1996. Heat shock elements are involved in heat shock promoter activation during tobacco seed maturation. Plant Mol. Biol. 31:157-162

Puzio, P. S., Lausen, J., De Almeida- Engler, J., Cai, D., Gheysen, G., and Grundler, F. M. W. 1999. Isolation of a gene from Arabidopsis thaliana related to nematode feeding structures. Gene 239:163-172.

Rieping, M., and Schöffl, F. 1992. Synergistic effect of upstream sequences, CCAAT box element and HSE sequences for enhanced expression of chimaeric heat shock genes in transgenic tobacco. Mol. Gen. Genet. 231:226-232.

Rojas, A., Almoguera, C., and Jordano, J. 1999. Transcriptional activation of a heat-shock gene promoter in sunflower embryos: synergism between ABI3 and heat shock factors. Plant J. 20:601-610.

Rombauts, S., Déhais, P., Van Montagu, M., and Rouzé, P. 1999. PlantCARE, a plant cis-acting regulatory element database. Nucleic Acids Res. 27:295-296.

Schöffl, F., Prändl, R., and Reindl, A. 1998. Regulation of the heat-shock response. Plant Physiol. 117:1135-1141.

Tada, Y., Wakasugi, T., Nishikawa, A., Furuhashi, K., and Yamada, K. 2000. Developmental regulation of a gene encoding a low-molecular weight heat-shock protein during haustorium formation in the seedling of a holoparasitic plant, Cuscuta japonica. Plant Cell Physiol. 41:13731380.

Urwin, P. E., Moller, S. G., Lilley, C. J., McPherson, M. J., and Atkinson, H. J. 1997. Continual green-fluorescent protein monitoring of cauliflower mosaic virus $35 \mathrm{~S}$ promoter activity in nematode-induced feeding cells in Arabidopsis thaliana. Mol. Plant-Microbe Interact. 10:394-400.

Vaghchhipawala, Z., Bassüner, R., Clayton, K., Lewers, K., Shoemaker, R., and Mackenzie, S. 2001. Modulations in gene expression and mapping of genes associated with cyst nematode infection of soybean Mol. Plant-Microbe Interact. 14:42-54.

Van der Eycken, W., De Almeida Engler, J., Inzé, D., Van Montagu, M., and Gheysen, G. 1996. A molecular study of root-knot nematode-induced feeding sites. Plant J. 9:45-54.

Wehmeyer, N., Hernández, L. D., Finkelstein, R. R., and Vierling, E. 1996. Synthesis of small heat-shock proteins is part of the developmental program of late seed maturation. Plant Physiol. 112:747-757.

Wehmeyer, N., and Vierling, E. 2000. The expression of small heat-shock proteins in seeds responds to discrete developmental signals and suggests a general protective role in desiccation tolerance. Plant Physiol 122:1099-1108.

Wingender, E., Chen, X., Hehl, R., Karas, H., Liebich, I., Matys, V., Meinhardt, T., Prüß, M., Reuter, I., and Schacherer, F. 2000. TRANSFAC: an integrated system for gene expression regulation. Nucleic Acids Res. 28:316-319.

Zimmerman, J. L., Apuya, N., Darwish, K., and O'Carroll, C. 1989. Novel regulation of heat-shock genes during carrot somatic embryo development. Plant Cell 1:1137-1146. 